\title{
Digital lectures for learning gross anatomy: a study of their efficacy
}

\author{
Anudeep Singh ${ }^{1}$ and Aung Ko Ko $\mathrm{Min}^{2}$ \\ Departments of ${ }^{1}$ Anatomy and ${ }^{2}$ Public Health, Mahsa University, Kuala Lumpur, Malaysia
}

Purpose: The current study investigates the level of students' learning and attitudes towards the teaching and learning process when using digital lectures to teach gross anatomy to year 1 medical students.

Methods: The study sampled year 1 medical students of cohorts 2013 and 2014. The year 1 medical students in 2013 were taught gross anatomy of the heart by didactic classroom lectures while those in 2014 were taught with digital lectures using the same content. A review session was conducted for the 2014 cohort. A 19-item survey was distributed amongst students to investigate their attitudes and feedback. The data were analysed using SPSS software.

Results: The 2014 cohort had a mean score of 47.65 for short essay questions and 51.19 for multiple choice questions, while the 2013 cohort scored an average of 36.80 for short essay questions and 49.22 for multiple choice questions. The difference in scores for each type of question was found to be significant. Using a 5-point Likert scale, students gave an average of 4.11 when asked if they liked the teaching and learning process and would like it to be applied further.

Conclusion: The results of the study provide strong evidence that the digital teaching and learning process was well received by students and could also lead to improved performance. Digital lectures can provide a satisfactory substitute for classroom lectures to teach gross anatomy, thus providing flexibility in learning and efficient learning, whilst also freeing lecture slots to promote mastery learning.

Key Words: Digital lectures, Teaching, Blended learning, Gross anatomy teaching, e-Learning

\section{Introduction}

Didactic lecturing is often criticised but still constitutes a major mode of teaching and constitutes "a defining element of most university courses [1].” Even with the introduction of new methods such as problembased learning, team-based learning, and the use of simulation when teaching medical students, the net effect has been limited [2]. Medical knowledge is ex- panding every day but there is a limited learning time for medical students. This calls for adoption of methods to make the lessons more compact and better use the students' time. One such method is to use digital media [3], presenting the lecture material synchronized with audio and video feed to the students. These digital lectures can be made available to the students online [4]. Doherty et al. [5] have discussed the use of tablet computing in learning. Tablets, with their long battery life, relatively large screens, large storage capacity, and
Received: July 26, 2016 • Revised: September 1, 2016 • Accepted: December 8, 2016 Corresponding Author: Anudeep Singh (http://orcid.org/0000-0002-9247-6860) Department of Anatomy, Mahsa University, Jalan University Campus, Jalan Elmu, Off Jalan University, Kuala Lumpur 59100, Malaysia

Tel: +60.379652555 Fax: +60.163546930 email: anudeep@mahsa.edu.my
Korean J Med Educ 2017 Mar; 29(1): 27-32.

https://doi.org/10.3946/kjme.2017.50

eISSN: 2005-7288

(C) The Korean Society of Medical Education. All rights reserved. This is an open-access article distributed under the terms of the Creative Commons Attribution Non-Commercial License (http:// creativecommons.org/licenses/by-nc/3.0/), which permits unrestricted non-commercial use, distribution, and reproduction in any medium, provided the original work is properly cited. 
fast processor speeds, bring new possibilities to medical education. Students can now learn anatomy using threedimensional interactive anatomy models which are available online. Many institutions are conducting online courses using digital lectures [6] and research is being conducted to explore the implementation and efficiency of digital lectures in everyday teaching and learning $[7,8]$. Technological advances support the efficient development of digital lecturing material by making both the necessary hardware [9] and the appropriate software widely available for easy viewing of digital lectures.

According to Demetriadis and Pombortsis [4], the three formats of technology-delivered lectures are: digital lectures - delivered synchronously or asynchronously; live digitized lectures - a digital version of the live event; and e-lectures - any digital learning resource in lecture format, captured in the studio. Though these methods have advantages within higher education, few authors have highlighted potential concerns related to learning issues, staff development and timetable coordination $[10,11,12]$. These issues can be addressed, as suggested by Prober and Khan [2] in 2013, if every organization makes video content of their own core curriculum.

Until 2013, the first-year students in our medical faculty were taught gross anatomy of the heart in the cardiovascular block through classroom lectures. In 2014, the classroom lectures were replaced with video lectures. Thus, the students were presented only with digital lectures of the same content. This study was conducted to investigate, firstly, if the digital lectures are as efficient as traditional lectures for our students' learning and, secondly, the level of students' satisfaction and their attitudes towards the use of digital lectures.

\section{Subjects and methods}

The study was conducted in Mahsa University in Kuala Lumpur, Malaysia. The study was given ethical approval by the university Research Review Committee. The same lecturer from the anatomy department who had been teaching gross anatomy of the heart to our medical students in previous years conducted the preparation and delivered both didactic and digital lectures, following and covering the learning objectives which were predefined by the subject experts of our medical school and keeping the content of lectures similar. All students from the cohorts of 2013/2014 ( $n=197)$ and 2014/2015 $(n=200)$ were included.

The digital-lectures were made using the video converter feature of PowerPoint 2007 software. The lecturer first prepared the gross anatomy lecture slides and then added narration to each slide, finally using the video converting the slide presentation into video presentation using PowerPoint. The subject of gross anatomy of the cardiovascular system was split into six smaller topics (digital lectures) which were (1) mediastinum (10 minutes and 30 seconds), (2) pericardium (8 minutes and 40 seconds), (3) external and internal structure of heart (15 minutes), (4) cardiac skeleton and valves (12 minutes and 40 seconds), (5) cardiac conduction system and nervous supply to heart (9 minutes), and (6) coronary blood supply (17 minutes and 30 seconds).

The total duration of the videos was 1 hour and 20 minutes. The emphasis was given to remembering the facts and understanding the conceptual knowledge, focussing on the first two cognitive levels of Bloom's revised taxonomy [13].

A preliminary test was conducted on samples from both cohorts before commencement of the module to establish the previous level of knowledge of gross 
anatomy of the heart. The cohort of 2013/2014, consisting of 197 students, was taught gross anatomy of the heart from didactic lectures during two 1-hour sessions on consecutive days. Later, a laboratory session of 2 hours was undertaken where students studied and discussed the subject using models and prosected specimens. The cohort of 2014/2015, consisting of 200 students, was only given digital lectures. The digital lectures were available on an external hard drive and were also uploaded onto the faculty server 1 week prior to the review session. A review was conducted during the 2-hour laboratory session where students were encouraged to clarify their doubts and pose questions. A short test containing 10 questions prepared by the author was given to the students which included three objective structured practical examination slides and seven multiple choice questions. Both of the test cohorts took an end-of-module examination on the cardiovascular system where students took the test for all the subjects studied during that module. The questions for the end-of-module examination for both years were prepared by subject experts in the department other than the author. The author was not involved in the collection and marking of the answer scripts. The results for the gross anatomy component of the end-of-module examination for both cohorts were collected and compared using independent t-test with SPSS version 9.0 (SPSS Inc., Chicago, USA).
Students in cohort 2014/2015 were asked to anonymously answer a Likert-scale feedback questionnaire using "survey monkey" (an online survey tool). The questionnaire was adopted from [4] with prior permission from the authors. The questionnaire contained 19 items under three main sections. Section I included students' attitudes towards the quality and use of digital lectures. Section II and section III included questions on positive and negative aspects of the use of digital lectures.

\section{Results}

A total of 197 and 200 students took the end-ofmodule examination from cohorts 2013/2014 and 2014/ 2015, respectively. Subject experts other than the author evaluated the answer scripts. The results of the cardiovascular gross anatomy component is presented in Table 1 as a percentage for each category of question. Significant differences between the two cohort groups were assessed using an independent two-tailed Student t-test.

\section{Questionnaire result}

The students of the 2014/2015 cohort were given the survey. Out of the 200 participants, 153 students completed the entire survey (76.5\%). A 5-point Likert scale was used (1, strongly disagree; 2 , disagree; 3 , undecided;

Table 1. Results of End-of-Module Examinations for the Cardiovascular Gross Anatomy Component as a Percentage in Each Category of Question

\begin{tabular}{clll}
\hline Question type & \multicolumn{1}{c}{ Cohorts } & Mean score & p-value \\
\hline SEO & $2013 / 2014(n=197)$ & $36.80 \pm 27.6$ & $<0.01$ \\
& $2014 / 2015(n=200)$ & $47.65 \pm 19.3$ & $<0.01$ \\
MCO & $2013 / 2014(n=197)$ & $49.22 \pm 11.46$ & \\
& $2014 / 2015(n=200)$ & $51.19 \pm 12.68$ & \\
\hline
\end{tabular}

Data are presented as mean \pm standard deviation.

SEQ: Short essay question, MCQ: Multiple choice question. 
Table 2. Students' Responses to the Attitude Questionnaire Regarding Digital Lectures ( $n=153$ )

\begin{tabular}{ccl}
\hline Item no. & \multicolumn{1}{c}{ Question } & \multicolumn{1}{c}{ Average rating } \\
\hline 1 & I consider the digitized lecture that I viewed as a positive learning experience. & $4.34 /$ agree \\
2 & Technically, the quality of the e-lecture was satisfactory. & $4.10 /$ agree \\
3 & I think that learning from digital lectures is in no aspect inferior compared to learning from & $3.58 /$ undecided \\
& a live lecture. & \\
4 & I think it is important to develop online e-lecture libraries. & $4.55 /$ strongly agree \\
5 & I think that viewing a digital lecture at home as many times as I wish gives me the opportunity & $4.55 /$ strongly agree \\
& to better reflect on the content of the lecture. & \\
I believe that combining digital lectures and classroom meetings for discussion can be a better & $4.47 /$ agree \\
& learning experience. & $4.11 /$ agree \\
\hline
\end{tabular}

Table 3. Students' Responses to the Attitude Questionnaire Regarding Positive Aspects of the Digital Lecture Experience ( $\mathrm{n}=153$ )

\begin{tabular}{cll}
\hline Item no. & \multicolumn{1}{c}{ Question } & Average rating \\
\hline 1 & Watching the e-lecture as many times one wishes results to better learning. & 4.54/strongly agree \\
2 & Ample time to get prepared and pose better stated questions. & 4.17/agree \\
3 & Better study conditions at home (feel more comfortable, better able to concentrate, do not get & 4.36/agree \\
& tired as in classroom, follow one's own pace). & \\
4 & With digitized lectures available one does not miss the lecturing event. & $4.32 /$ agree \\
5 & Able to review the e-lecture material without bothering the teacher. & $4.12 /$ agree \\
6 & Feel motivated by the use of audiovisual technology. & $4.11 /$ agree \\
7 & e-Lecture enables participation and so it is more interesting. & 4.14/agree \\
\hline
\end{tabular}

Table 4. Students' Response to the Attitude Questionnaire Regarding Negative Aspects of the Digital Lecture Experience ( $n=153$ )

\begin{tabular}{cll}
\hline Item no. & \multicolumn{1}{c}{ Question } & \multicolumn{1}{c}{ Average rating } \\
\hline 1 & Lack of immediate discussion. & $3.46 /$ undecided \\
2 & Excessive comfort at home may promote procrastination. & $3.56 /$ undecided \\
3 & More pleasant to attend a live lecture than a digitized one. & $3.19 /$ undecided \\
4 & When digital lectures become an everyday routine, they may lose their appeal. & $3.28 /$ undecided \\
5 & Better to have both live lectures and digital lectures las supporting materiall. & $4.54 /$ strongly agree \\
\hline
\end{tabular}

4, agree; 5, completely agree).

Table 2 shows the students' responses to the attitude questionnaire regarding the digital lectures $(n=153)$. Tables 3 and 4 show the students' responses to the attitude questionnaire regarding positive and negative aspects of the digital lecture experience, respectively $(n=153)$.

\section{Discussion}

The results of the present study are in concordance with the meta-analysis study published by the Department of Education which had concluded that "on average, students in online learning conditions performed modestly better than those receiving face-toface instruction," with larger effects if the online learning was combined with face-to-face instruction [14].

In the present study, we strove to establish flexibility and cohesiveness of the various learning events. In implementing this approach, we explored the efficiency of short digital lectures as learning material within the context of specific blended learning activities. In the present study, the quantitative data suggests that there is 
a significant difference in the learning outcomes of the two cohorts, as measured by results of the end-ofmodule examination used to determine the students' level of understanding. Our data contradicts the general view that digital lectures produces results on par with traditional teaching, as it shows a significant increase in academic performance when compared to results of face-to-face lectures [15]. The results for the summative assessment show statistically significant improvement compared to other studies [4].

The qualitative data also suggests that digital lectures seem to be an acceptable alternative to face-to-face delivery, as is agreed by other studies [15,16], even though the students are strongly in favour of having both. This preference is believed to be due to the fact that our students are more in the practice of getting lecture slides as learning material, but it is considered that as more and more topics/subjects are delivered with video lectures, their attitude will change. They agreed that they would like it to be applied to all teaching and that digital lectures can serve as an adequate replacement for classroom lectures. Students agreed that the digital lectures are a positive learning experience and that combining digital lectures and review sessions for discussion can be a better learning experience as they provide more time and the convenience of viewing the presentations anytime. This shows that they value the flexibility provided by video lectures and also that the concept of flipping the classroom is much appreciated. Students also voted strongly in favour of developing an online e-lecture library as has been suggested by Prober and Khan [2], which gives them an opportunity to better reflect on the content of the lecture and also to revisit the lectures anytime. They also strongly agreed with the convenience of the ability to keep copies of these presentations for use in the future.

Our study shows that our students favored the digital format of lectures which is in conjunction with several previous studies $[17,18,19]$. Digital lectures can replace didactic teaching, providing more time in the curriculum for other interactive sessions/modalities of teaching and learning. On the other hand, creating digital lecture libraries can be useful for both educators and students for learning basic knowledge and presentation skills [20].

A limitation of our study was that the digital lectures produced all used same format, though our results can provide basis for further studies to investigate the effect of different types of media to capture videos or make synchronous online learning resources which can be delivered remotely, away from university. Another important question that needs to be answered in future studies concerns the retention of teaching material over longer periods of time and whether these lectures are revisited by students during their clinical years.

This study provides evidence that digital lectures can be safely used as students' introductory learning material for gross anatomy teaching, thus increasing flexibility of knowledge acquisition and enhancing motivation, which can lead to better results.

ORCID: Anudeep Singh:

http://orcid.org/0000-0002-9247-6860;

Aung Ko Ko Min: http://orcid.org/0000-0003-0963-4213

Acknowledgements: The authors acknowledge the help and guidance provided by the head of department professor Dr. Subramaniam.

Funding: None.

Conflicts of interest: None.

\section{References}

1. Bell T, Cockburn A, McKenzie B, Vargo J. Digital 
lectures: if you make them, will students use them? Constraints on effective delivery of flexible learning systems. Interact Multimed Electron J Comput Enhanc Learn 2001; 3.

2. Prober CG, Khan S. Medical education reimagined: a call to action. Acad Med 2013; 88: 1407-1410.

3. Prober CG, Heath C. Lecture halls without lectures: a proposal for medical education. N Engl J Med 2012; 366: 1657-1659.

4. Demetriadis S, Pombortsis A. E-lectures for flexible learning: a study on their learning efficiency. Educ Techno Soc 2007; 10: 147-157.

5. Doherty I, Sharma N, Harbutt D. Contemporary and future eLearning trends in medical education. Med Teach 2015; 37: 1-3.

6. Rui Y, Gupta A, Grudin J, He L. Automating lecture capture and broadcast: technology and videography. Multimedia Syst 2004; 10: 3-15.

7. Dev P, Rindfleisch TC, Kush SJ, Stringer JR. An analysis of technology usage for streaming digital video in support of a preclinical curriculum. Proc AMIA Symp 2000: 180-184.

8. Spickard A 3rd, Alrajeh N, Cordray D, Gigante J. Learning about screening using an online or live lecture: does it matter? J Gen Intern Med 2002; 17: 540-545.

9. Joukov N, Fauster M, Chiueh TC. Design, implementation, and evaluation of a digital lectern system. Paper presented at: International Conference on Web-based Learning (ICWL 2003); 2003 August 18-20; Melbourne, Australia.

10. Carville S, Mitchell DR. 'It's a bit like Star Trek': the effectiveness of video conferencing. Innov Educ Train Int 2000; 37: 42-49.

11. Freeman M. Video conferencing: a solution to the multi-campus large classes problem? Br J Educ Technol 1998; 29: 197-201.
12. Pitcher N, Davidson K, Napier JG. Videoconferencing in higher education. Innov Educ Train Int 2000; 37: 199-209.

13. Anderson LW, Krathwohl DR, Airasian PW, Cruikshank KA, Mayer RE, Pintrich PR, Raths J, Wittrock MC. A taxonomy for learning, teaching, and assessing: a revision of Bloom's taxonomy of educational objectives. New York, USA: Longman; 2001.

14. Evaluation of evidence-based practices in online learning: a meta-analysis and review of online learning studies [Internet]. U.S. Department of Education, Office of Planning, Evaluation, and Policy Development; c2010 [cited 2012 May 3]. Available from: http://www2.ed.gov/ rschstat/eval/tech/evidence-based-practices/finalreport.pdf.

15. Solomon DJ, Ferenchick GS, Laird-Fick HS, Kavanaugh K. A randomized trial comparing digital and live lecture formats. BMC Med Educ 2004; 4: 27.

16. Callas PW, Bertsch TF, Caputo MP, Flynn BS, DohenyFarina S, Ricci MA. Medical student evaluations of lectures attended in person or from rural sites via interactive videoconferencing. Teach Learn Med 2004; 16: $46-50$.

17. Mattick K, Crocker G, Bligh J. Medical student attendance at non-compulsory lectures. Adv Health Sci Educ Theory Pract 2007; 12: 201-210.

18. Whitten P, Ford DJ, Davis N, Speicher R, Collins B. Comparison of face-to-face versus interactive video continuing medical education delivery modalities. J Contin Educ Health Prof 1998; 18: 93-99.

19. Nikopoulou-Smyrni P, Nikopoulos C. Evaluating the impact of video-based versus traditional lectures on student learning. Educ Res 2010; 1: 304-311.

20. Caspi A, Gorsky P, Privman M. Viewing comprehension: students' learning preferences and strategies when studying from video. Instr Sci 2005; 33: 31-47. 